Original article

\title{
Later life civic engagement of elderly in Ahwaz -Iran
}

\author{
Abdolrahim Asadollahi', Laleh Fani Saberi ${ }^{2, *}$, Farideh Rezaie Abhari ${ }^{3}$, Fatemeh Shirinkam ${ }^{4}$
}

(Received: 9 Jun 2013; Accepted: 11 Sep 2013)

\begin{abstract}
Background and Purpose: The problematic reduction of civic engagement in local communities of Khuzestan province in the southwest of Iran has became a serious issue for research in social planning and policy making. Efforts have been made to study the risk factors as the deterrents to engaging in the society.
\end{abstract}

Methods: this study aims to investigate the factors influencing civic engagement among elderly citizens, focusing on the role of the background variables and individual characteristics as the reducing or active factor. The community of study is 201 elderly citizens from the selected urban areas of Ahwaz city selected through cluster sampling method. The independent variables are gender, socioeconomic status, membership in non-governmental organizations (NGOs), and the duration of living in the city, the sense of satisfaction of urban services, traditionalism, and fatalism.

Results: It was observed that some independent variables have no significant relationship with civic engagement of the elderly, though elders have fewer participating interactions in this study.

Conclusion: Some proposals within the research itself were recognized as potential improvement and reinforcement energies to participation-based planning in the population, especially among women and the elderly. The growth of social networks and societal links, along with social trust revival seemed helpful.

Keywords: Enabling factors, Social participation, Elderly, Cross-sectional studies, Disability evaluation, Interpersonal relations, Social behavior, Socioeconomic factors, Public health, Iran

\section{Introduction}

"Lack of activity destroys every person's well being, while movement and regular physical exercise saves and preserve it." Plato (429-347 B.C.E.). Aged citizens display many variations in the form of continuation, substitution, or curtailment in the course of their engaging patterns in their later life. The number of activities in which they participate and their intensity is declining (1-5). They have stated the positive relationships among staying active at older age and the development of health, self fulfilment, selfesteem, a sense of freedom, having social contacts, and personal well being (6-11).

Hence in an interesting example, Towers (12)and Asadollahi (13-14) investigated people in their 70s to 90s (12-14). They found that spiritual beliefs and in particular, religious association over life span had a positive impact on older people's transition to care (12-14). Specifically, being in contact with spiritual matters sustained a sense of confidence in

${ }^{1}$ Department of Social Gerontology, ACQOL, Deakin University, Melbourne, Australia.

${ }^{2, *}$ Corresponding author: Department of Community Health, Nursing and Midwifery School, Mazandaran University of Medical Sciences, Sari, Iran.

Department of Health Promotion, Tehran University of Medical Sciences, Tehran, Iran. Email: fanisaberi@yahoo.com.

${ }^{3}$ Department of Midwifery, Nursing and Midwifery School, Mazandaran University of Medical Sciences, Sari, Iran.

${ }^{4}$ Department of Midwifery, Ramsar Nursing and Midwifery School, Babol University of Medical Sciences, Babol, Iran. 
self, and a belief that life still matters and is purposeful. Religious affiliations provided a sense of order in their experience, so that the time in care was still a period when old connections sustained. Religion gives elderly people in nursing homes a sense of homeostasis, a balance between their internal selves and their external environment. There are a number of reports in the literature on the psychological and physical benefits of religion and spirituality, with specific focus on older people, some of which could help mediate the effects of a potential traumatic event such as change of residential place (15-18).

For example, a study by Chokkanathan (2013) that employed their original spirituality measure, revealed positive the relationships between core spiritual experiences and both life satisfaction and reduction of medical symptoms scores in participants aged 25 to 72 years (19).

Wang, Kercher, Huang, and Kosloski (2013), in their research on coping with deteriorating neighbourhoods, found that people over age 65 who were involved in church (that is, organised religious services) were less likely to experience a decline in their self-rated health status than those with weak institutional ties (20). Krause argued that the feeling that one is not alone during unpleasant times plus the presence of like-minded people, who can provide social support, is behind this finding. Although not specifically focused on religion, studies by Kahn, Hessling, and Russell (2003) on elderly people found significant relationships between perceived social support and measures of psychological wellbeing but, interestingly, not between the former and self-rated physical health after controlling negative affectivity (21).

Zenevicz L, Moriguchi Y, Madureira (2013) carried out several investigations on the benefits of religion to the elderly For example, he reported that nearly the majority of the aged had indicated that they used religion to help them cope, with half of these stating that it was the most important factor that kept them going (22). Among the evidence cited is the notion that religious beliefs may provide older people with a form of control over health matters that their non-religious peers do not have, and that religious activities might even be associated with longer survival of up to 7 years (23).

So far, Corrêa, Moreira-Almeida, Menezes, Vallada, and Scazufca (2011) not only stated that older adults who were more satisfied with their lives reported the greatest number of activities conducted at least weekly and more various activity participation, but also that participation benefited these older adults physiologically, psychologically, socio-culturally, developmentally, and spiritually (24). A much less developed theme is the spatial diversity related to the participation of old people (25-28). Thus, the social interactions are reflected into the concept of 'sociability', which sociological theorist, Simmel (1950) defined as the "interaction that exists for its own sake" \& it's spoiled if its contents grow significantly or its emotional impact gets too strong, and that is separated from interaction solely geared to providing or receiving information" (29). The fact that activities are tied to time and space as extensively described in time-space geography. They actually have an important consequence. On the one hand, there are specific types of an activity associated with specific socio-spatial domains and health status of the aged (30-31).

On the other hand, the world is rapidly ageing: the number of people aged 60 and over as a proportion of the global population will double from $11 \%$ in 2006 to $22 \%$ by 2050 . By then, there will be older people than children (aged 0-14 years) in the population for the first time in human history (32). Developing countries are ageing at a much faster rate than developed countries; within five decades, just over $80 \%$ of the world older people will be living in developing countries compared with $60 \%$ in 2005 (33). At the same time, our world is a growing city: as of 2007 , over half of the global population now 
live in cities [33]. Mega-cities, that is, cities with 10 million inhabitants or more, increased ten-fold from 2 to 20 during the 20th century, accounting for $9 \%$ of the world urban population by 2005 (33). The number and proportion of urban dwellers will continue to go up over the coming decades and particularly in cities with fewer than 5 million inhabitants (34). Again, this growth is happening much faster in developing regions. By 2030, about three out of every five people in the world will live in cities and the number of urban dwellers in the less developed regions will almost be four times as large as that in more developed regions (32).

The connection within social participation, civic engagement, and aging is referred as active aging and aged friendly-city as well. Active ageing is the process of optimizing opportunities for health, participation and security in order to enhance quality of life as people age and recently, it has turned as a common reliable concept in literatures and research in the field of Social Gerontology (35-42). In an agefriendly city, policies, services, settings and structures support and enable people to age actively by:

- Recognizing the wide range of capacities and resources among older people;

- Anticipating and responding flexibly to ageingrelated needs and preferences;

- Respecting their decisions and lifestyle choices;

- Protecting those who are most vulnerable;

- Promoting their inclusion in and contribution to all areas of community-based life (43).

Active ageing depends on a variety of influences or determinants surrounding individuals, families and nations. They include material conditions as well as social factors that affect individual types of behaviour and feelings (44). All of these factors and the interaction between them play an important role in affecting how well individuals get aged. Many aspects of urban conditions and services reflect these determinants that are included in the characteristic features of an aged-friendly city (44).
A similar form of activity which involves social interaction among the elderly was also studied by Silverstein and Parker (45) and Triado et al. (46). Triado et al. (46) reported that $43.5 \%$ of the rural elderly in Spain spent time talking with others in an ideal day. The elderly also allocated less time to passive activities such as watching TV or resting in the ideal day and spent more time on socializing (46).

Social interaction with friends was also the most common activity performed by the very old elderly in Sweden (45). Although it is passive and sedentary in nature, various benefits can be gained from social activities even if it only involves simple informal social interactions or conversations. A critical review by Adams et al. (47) had suggested that an informal social interaction was the most evident activity affecting the well-being of an individual (47), and especially, minority aging groups (48).

In addition, participatory action and everyday life activity are connected to the basic concept of healthy and successful aging. It means aging without chronic illness and disability. Another approach is to think of healthy aging as maintaining well-being in all spheres of life as physical, mental, and social. Assessing and conducting research on active ageing could support elderly people to use new findings of research and also decision makers and carers to decide better administration for older adults 'well-being. Some key points approved the connection between engaging in the community and well-being of older adults and the necessity of research on this issue as following (43-45). First of all, regular physical activity, of even a more moderate intensity, is an established independent risk factor for a range of chronic diseases and conditions associated with aging. Second, in a growing number of countries, middle aged and older adults represent the most inactive segment of the population. And third, to address global physical inactivity crisis among older populations and the other community members, a systematic approach that applies a multi-level ecological framework and 
an array of actions aimed at science, policy, and practice is needed (49-50).

With a population of 73 million, a natural growth rate of $1.08 \%$, and domestic production as measured by GDP of US\$115 billion, Iran emerges as the second most populous country with the second largest economy in the Middle East at the end of 2006 (51). The nation is the second largest oil producer within OPEC and has the world's second largest reserves of gas (52-53). The literacy rate is more than 79 per cent and the structure of the school system is eight years of compulsory primary and lower secondary education as well as three years of optional upper-secondary education. There are approximately 18 million students in school and about 1.7 million in the universities (51).

According to the World Bank Report (2005) and ISCC (2007), Iran has emphasized human development and social protection with good progress to date. For example, from early 1970s to 2001, primary school enrolment rates increased from 60 to $90 \%$ and the portion of the population living below the poverty line decreased significantly from $47 \%$ in 1978 to $16 \%$ in 1999 . However, data shows an increase of the elderly population from $1.3 \%$ in 1997 to $2.8 \%$ in 2007 , which indicates an increase in DR (dependency ratio) above 55 years old among Iranian Citizens (51-52). Likewise, as shown by the Khuzistan Census of 2007, DR has increased from $1.6 \%$ to $3.1 \%$, which is more than the national average for the period from 1997 to 2007 (54).

The community of this study is the elderly population above 60 years old in Ahwaz, the provincial capital of Khuzestan province in southwest Iran near Iraq/ Iran border and north of the Persian Gulf. During the years 1997 to 2011 census, Ahwaz district showed a higher ratio of aged persons among all cities of Khuzestan province $(3.1 \%$ in total aged population of the province) and the Khuzestan province was ranked as the second group of aged populated provinces. All data was based on KSCC and ISCC annual reports in 2007 and 2011 (54-55). The research aimed to estimate the effective factors affecting the civic engagement and participation of the elderly citizens in the community of Ahwaz city.

\section{Materials and Methods}

The samples include 201 aged persons comprising 98 aged women and 103 aged men in four urban areas. The dwellers of Ahwaz accepted positively to participate in this study (see table 1) (54).

Table 1. Sample Size \& Percentage of Each Gender for Aged Citizens in 4 Urban Areas

\begin{tabular}{|c|c|c|c|c|c|}
\hline \multirow[b]{2}{*}{$\begin{array}{l}\text { Ahwaz } \\
\text { Urban } \\
\text { Areas }\end{array}$} & \multirow[b]{2}{*}{$\begin{array}{l}\text { Total } \\
\text { population }\end{array}$} & \multirow[b]{2}{*}{$\begin{array}{c}\text { Percentage } \\
\text { for each } \\
\text { area }\end{array}$} & \multirow{2}{*}{$\begin{array}{l}\text { Samples for } \\
\text { each area } \\
\text { based on the } \\
\text { percentage } \\
\text { ratio }\end{array}$} & \multirow{2}{*}{\multicolumn{2}{|c|}{$\begin{array}{l}\text { Male Female } \\
\text { Samples based on } \\
\text { the percentage of } \\
\text { third colum } n\end{array}$}} \\
\hline & & & & & \\
\hline $1^{\mathrm{st}}$ & 8283 & 16.24 & $\begin{array}{c}\text { rantio } \\
62\end{array}$ & 31 & 31 \\
\hline $2^{\text {nd }}$ & $\begin{array}{l}8383 \\
3844\end{array}$ & 7.451 & 0 & 0 & 0 \\
\hline $3^{\text {rd }}$ & $\begin{array}{l}3844 \\
7871\end{array}$ & 15.25 & 58 & 29 & 27 \\
\hline $4^{\text {th }}$ & $\begin{array}{l}7871 \\
0516\end{array}$ & 16.53 & 0 & 0 & 0 \\
\hline $5^{\text {th }}$ & $\begin{array}{l}8516 \\
3132\end{array}$ & 6.017 & 23 & 12 & 12 \\
\hline $6^{\text {th }}$ & $\begin{array}{l}3132 \\
0160\end{array}$ & 17.75 & 0 & 0 & 0 \\
\hline $7^{\text {th }}$ & 9160 & 15.16 & 58 & 31 & 28 \\
\hline $8^{\text {th }}$ & $\begin{array}{l}7824 \\
2864\end{array}$ & 5.515 & 0 & 0 & 0 \\
\hline Total & $\begin{array}{l}2804 \\
51594\end{array}$ & 100 & 201 & 103 & 98 \\
\hline
\end{tabular}

Data adopted from local \& national census bureaus [54-55].

All respondents aged 60 years of old and above were married and had brought up children that have been selected through stratified random sampling method. Data collection has used an instrument made up of theoretical background and reviews by the authors namely ACES (Aging Civic Engagement Scale). The respondents who were literate responded to the instrument, but the illiterate aging samples completed the scale by supporting the experienced interviewers with full consent and authority in a quiet stress-free space and with an emphasis on their rights to privacy. It has five sectors, i.e., participating in governmental sectors, participating in communal sectors, participating in religious and common wealth sectors, participating in charity sector, 
and a part by asking background and individual characteristics of samples as independent variables. The respondents replied to 24-item questionnaire with five-point Likert scale from 'strongly agree' to 'strongly disagree'.

Regarding the content validity, the questionable cases were referred and approved by the judges for two times. According to Mack, Woodsong, MacQueen, Guest, and Namey (2005), 35 judges and experts were selected (55). During the content validity of the scale, the criteria for the jury selection had at least three of the following characteristics:

[1] Holding at least a master's degree in health science or related fields.

[2] Doing research and scientific work.

[3] Having an article or book written or translated into Persian.

[4] Teaching experience in the related field in Gerontology and Aging.

[5] Being a faculty member in any department of related fields.

In the end, the coefficients have been calculated after collecting judges and referees opinions. The content validity coefficient items and content validity coefficient scale were obtained by following formula (see Fig.1):

$$
C V C=\frac{\overline{C V C I}+C V C S}{2}=\frac{65.2+74.51}{2}=69.85
$$

Figure 1. The Content Validity of ACES by CVCI \& CVC

The values of Fig. 1 indicate the utility and validity of ACES. Accordingly, the reliability of ACES is the second target for evaluating the scale. According to table 2, $\alpha$-Cronbach's of the dependent variable, civic engagement worked out at 0.78 , with the corrected item total correlation between the statements in $0.35-0.51$ interval.
Table 2. Internal Reliability for Four Basic Indicators of ACES* $(\rho=.000, \mathrm{df}=201)$

\begin{tabular}{|c|c|c|c|c|c|}
\hline $\begin{array}{c}\text { Basic items of } \\
\text { ACES }\end{array}$ & $\begin{array}{c}\text { No. of } \\
\text { Q. }\end{array}$ & $\begin{array}{c}\mathrm{M} \\
\text { (SD) }\end{array}$ & Skewness & Kurtosis & Alpha \\
\hline $\begin{array}{l}\text { Participating in } \\
\text { governmental } \\
\text { sectors }\end{array}$ & 6 & $\begin{array}{l}2.29 \\
(.68)\end{array}$ & .43 & .25 & .70 \\
\hline $\begin{array}{l}\text { Participating } \\
\text { in communal } \\
\text { sectors }\end{array}$ & 6 & $\begin{array}{l}2.58 \\
(.62)\end{array}$ & -.56 & .33 & .71 \\
\hline $\begin{array}{l}\text { Participating in } \\
\text { religious sectors }\end{array}$ & 6 & $\begin{array}{l}3.78 \\
(.72)\end{array}$ & -.47 & .35 & .74 \\
\hline $\begin{array}{l}\text { Participating in } \\
\text { charity sectors }\end{array}$ & 6 & $\begin{array}{l}3.35 \\
(.88)\end{array}$ & .41 & -.31 & .69 \\
\hline ACES & 24 & $\begin{array}{l}3.02 \\
(.79)\end{array}$ & .38 & .37 & .78 \\
\hline
\end{tabular}

ACES is adopted from "Putnam and Knock theory "about participatory actions and social participation issues (56-57). They have a relative definition for CE throughout social capital theory. The CIRCLE (57) defined $\mathrm{CE}$ and its indicators as independent components for interaction behaviour of citizens in their communities (57). The citizens are viewed as agent actors in society, politically and socially (58). According to these background information, KSCC (2007) conducted some indicators that measure participatory interactions, social involvement, volunteering in non-profit groups, and the like (54).

ACES was well adjusted for the Iranian samples in 2012 by Mohammadi (58) to assess participatory actions of citizens in the political and social domains $(\alpha=.72)$. Mohammadi's ACES was conducted in two parts, participating in governmental groups and communal groups and with 11 queries that ask participants about engaging in eight civic groups, e.g. sport groups, social clubs and NGOs, local communities or neighbourhood groups, religious groups, charity and/or non-profit groups, work and/or occupational groups, and political groups [58]. The score is ranked between 24 as low and 120 as high. 
The lower score means the participant has low degree in CE and its reliable coefficient is well conducted.

ACES has two main domains. The first domain, participating in governmental groups contains six items with five parts, i.e., as $1=$ not at all, $2=\mathrm{a}$ little bit, $3=$ medium, $4=$ quite a lot, and $5=$ very much in response options and total score ranked between 6 and 30, with 6 meaning the least engaging in governmental groups and 30, the highest engaging. The second domain, participating in communal groups contains eight items with three parts, such as $1=$ never, $2=$ sometimes, and $3=$ often in response options for the first seven items. The eight nominal items are open-ended questions as engaging in the other groups. The majority of the respondents didn't reply to this item, so the researcher has omitted the open-ended items in the last contribution and discussion. Total score ranked between 7 and 21, with 7 meaning the least engaging in communal groups and 21 as the highest engaging.

ACES was validated, too $(\alpha=.78, \rho=0.000, \mathrm{df}=201)$. According to table 2, internal validity based on alpha Cronbach's is well adjusted to four basic indicators of ACES. Items of ACES are reliable. Overall, scores indicate that these concepts were moderately internally consistent. The study has mentioned a new definition for civic engagement in the Gerontological aspect. Religious affiliation was recorded as Muslim totally. Thus, the participant sample was deemed to be homogenous. Participants were sought from different areas and from the selected urban areas in Ahwaz city. The data was interpreted by the latest statistical software of SPSS V. 21 and the correlation coefficients, central tendency and dispersed tests were used in evaluating them.

\section{Results}

In this research, 32.4 per cent of men and 64 per cent of women were widow, $23.4 \%$ self-employed, $29.8 \%$ of samples mentioned that they have chronic diseases (see table 3). The age rang was 60 to 94 years old $(M=71.07$ years old, male age mean $=67.3$ and female age mean $=74.01)$. Data analysis based on T-test showed that male elders have more participation than the female ones $(t=2.718, \rho=.006)$.

Table 3. Demographic Characteristics of Aged Samples

\begin{tabular}{|c|c|c|c|}
\hline \multicolumn{2}{|c|}{ Demographic Items } & \multirow{2}{*}{$\begin{array}{l}\mathbf{N} \\
103\end{array}$} & \multirow{2}{*}{$\begin{array}{c}\mathbf{\%} \\
52.7\end{array}$} \\
\hline \multirow[b]{2}{*}{ Gender } & Male & & \\
\hline & Female & 98 & 47.3 \\
\hline \multirow{5}{*}{ Age } & 60 to 64 & 102 & 51.0 \\
\hline & 65 to 69 & 30 & 15.1 \\
\hline & 70 to 74 & 28 & 14.1 \\
\hline & 75 to 79 & 26 & 12.8 \\
\hline & 80 and above & 15 & 7.0 \\
\hline \multirow{5}{*}{ Marital status } & Single & 7 & 2.8 \\
\hline & Married & 161 & 79.9 \\
\hline & Divorced & 5 & 2.5 \\
\hline & Widow & 26 & 13.0 \\
\hline & No answer & 2 & 1.8 \\
\hline \multirow{5}{*}{ Education } & Illiteracy & 73 & 36.3 \\
\hline & Elementary & 35 & 17.5 \\
\hline & Secondary & 53 & 26.6 \\
\hline & High & 32 & 16.0 \\
\hline & University & 8 & 3.5 \\
\hline \multirow{3}{*}{ Retirement status } & Not retired & 54 & 26.8 \\
\hline & Retired & 99 & 49.1 \\
\hline & Others* & 48 & 24.1 \\
\hline \multirow{5}{*}{ Income } & Pension & 29 & 14.6 \\
\hline & Personal savings & 71 & 35.1 \\
\hline & $\begin{array}{l}\text { Supported by } \\
\text { children/relatives }\end{array}$ & 43 & 21.5 \\
\hline & Salary & 45 & 22.5 \\
\hline & Others & 13 & 6.3 \\
\hline \multirow{4}{*}{$\begin{array}{l}\text { Having chronic diseases } \\
\& \text { time }\end{array}$} & 5 years and less & 104 & 51.6 \\
\hline & 6 to 10 years & 24 & 12.1 \\
\hline & 11 years and above & 21 & 10.5 \\
\hline & No chronic diseases & 52 & 25.8 \\
\hline \multirow{5}{*}{ Annual income } & $\$ 1400$ and less & 107 & 53.5 \\
\hline & $\$ 1401$ to $\$ 2000$ & 69 & 34.4 \\
\hline & $\$ 2000$ to $\$ 3000$ & 18 & 8.8 \\
\hline & $\$ 3001$ to $\$ 4000$ & 5 & 2.3 \\
\hline & \$4001 and above & 2 & 1 \\
\hline
\end{tabular}

$*$ Females who had never worked.

According to table 3, there were few differences between men and women in the level of social participation. As table 4 shows, Pearson correlation 
coefficient at $r=.74$ and $(\rho=.000<.05)$ indicates that there is a positive and significant relationship between independent variable (health status) and dependent variable (civic engagement of older adults). Also, when social contact \& interpersonal trust is more, there is more tendency to the civic engagement of older adults. Pearson correlation coefficient at, $\mathrm{r}=.52, \alpha=.000$, and (sig=.000<.01) shows that there is a positive and significant relationship between (independent variable) social solidarity \& interpersonal trust civic engagement of older adults (dependent variable).

Table 4. Relationship between ACES and the background factors

\begin{tabular}{|c|c|c|c|c|c|c|}
\hline Dependent Variable & $\begin{array}{c}\text { No. } \\
\text { of } \\
\text { Item }\end{array}$ & M (SD) & $\mathbf{N}$ & $\mathbf{r}_{\mathrm{p}}{ }^{\mathrm{a}}$ & DF & $\rho$ \\
\hline ACES $^{\circ}$ & 24 & $125(8)$ & 201 & .814 & 172 & .0001 \\
\hline \multicolumn{7}{|l|}{$\begin{array}{l}\text { Independent } \\
\text { Variables }\end{array}$} \\
\hline Gender & 1 & 11(3) & 201 & 2.718 & 173 & .0016 \\
\hline Health status & 4 & $24(12)$ & 200 & .014 & 171 & .0704 \\
\hline $\begin{array}{l}\text { A sense of belonging } \\
\text { to the one'sciety }\end{array}$ & 6 & $28(11)$ & 200 & .521 & 170 & .0018 \\
\hline & 4 & $21(8)$ & 201 & .523 & 172 & .0001 \\
\hline $\begin{array}{l}\text { Traditionalism \& } \\
\text { fatalism }\end{array}$ & 2 & $8(2)$ & 199 & -.762 & 169 & .0015 \\
\hline SES & 5 & 23(7) & 201 & .453 & 172 & .0006 \\
\hline $\begin{array}{l}\text { A sense of } \\
\text { satisfaction with }\end{array}$ & 7 & $29(6)$ & 201 & .654 & 172 & .0012 \\
\hline $\begin{array}{l}\text { urban services } \\
\text { Duration of living in } \\
\text { the city }\end{array}$ & 2 & $7(2)$ & 196 & .381 & 160 & .0002 \\
\hline NGOs membership & 3 & $12(3)$ & 201 & .112 & 172 & .0304 \\
\hline Religiosity & 3 & $15(5)$ & 195 & -.102 & 166 & .0151 \\
\hline
\end{tabular}

According to table 4 , the traditionalism \& fatalism among aging adults has reverse relationship with the civic engagement of the aged. Pearson correlation coefficient test of the civic engagement of older adults, social contact $\&$ interpersonal trust at $\mathrm{r}=-.76, \alpha=.000$ resulted a significant inverse correlation. Also, when the socio-economic status of older adults was not high, the less it is drawn to the civic engagement of them. Socio-economic status and the civic engagement of older adults $r=.45, \alpha=.006$ point to a significant correlation.

If the sense of satisfaction with urban services is high, the more it is drawn to the civic engagement of ageing people. Pearson correlation coefficient test of the variables, a sense of satisfaction with urban services and the civic engagement of older adults at $\mathrm{r}=.65, \alpha=.001$ brought out a significant relationship correlation. When the duration of living in the city is high, it is drawn more to the civic engagement of ageing. Pearson correlation coefficient test of the variables as duration of living in the city and the civic engagement at $r=.38, p=.0002$ resulted a significant relationship correlation. The results imply that when older adults have a membership of NGOs, the more they are attracted to the civicengagement. Pearson correlation coefficient test of the variables as membership of the elderly in NGOs and the civic engagement of older adults at $r=.112, \alpha=.0304$ point to a significant correlation.

Additionally, there is no significant relationship between religiosity and civic engagement of older adults. The Pearson correlation coefficient test of the variables elder's membership in NGOs and the civic engagement of older adults at $\mathrm{r}=-.102$, $\alpha=.045$, pointed there is not significant correlation between the religiosity and older adults' social participation. It was observed that religious elders have fewer participatory social interactions.

However, everyone who has defined him/herself as non-religious citizen was almost at the same level. Generally, religiosity is a neutral variable and insignificant for increasing or reducing civic engagement of the elderly citizens. It means that each side of the religious behaviour scale has the least impact on civic engagement of older adults in Ahwaz.

\section{Discussion}

There are many ways of describing older adults' engagement in social activities and the type and number of social connections they maintain. About 86.5 per cent of aged samples visit their family and friends once a week or more. The visiting rate increases with age and women visit with family and friends more repeatedly than men. One in five older people aged 67-78 do voluntary work at least once a week or more. Participation in formal organised activities including voluntary activities is at peak among older adults with 
high levels of education, widowhood and high level of well-being. Similar proportions of older men and women (approximately 14.7\%) are engaged in high greater charitable interactions and membership of NGOs. A sense of belonging to one's city increases with better communal assimilation while it decreases with the level of religiosity, a sense of belonging to one's city, and social contact \& interpersonal trust. About $12 \%$ of elderly female and $9 \%$ of older men stated that they are socially secluded and have had feeling social exclusion. Elderly people with poorer selfrated health, SES, income, having long time chronic diseases are most likely to be socially isolated. Among the $86.7 \%$ of older Ahwazi population reported being religious and $76 \%$ are present at the religious services at least once a week. Nearly $84 \%$ of people aged 78 and above attend a religious service once a week or more. Over $71 \%$ of older adults voted in 2007 to 2011 political election and had formal participation.

The fact that education, income and health status have positive relationship with participation in activities such as culture, outdoor activities and sports can signify that future old people will be able to maintain a more varied package of activities that has been supported by the most recent literatures (32$33,36-39,45-48)$. So far, contraction and convergence operate more strongly because health limitations and inevitable aging itself will continue to exert a negative effect on participation. Old people who combined many activity types when younger may have to ignore more of them as limitations increase with aging. Hence, it reveals the distance of the urban elderly from social interactions and citizenship participation arenas where they might go face to face with younger adults and juveniles as recent works acclaimed (14, 6-11, 20-22).

This distance could negatively influence social control and collective consciousness. Aggregation of population with overall social anonymity, individualism with centricity of personal interest and ascendancy of a vertical hierarchy with social discrimination have the main effect of reducing civic engagement in Iranian urban areas, hence it was approved by contemporary literatures (13-14, 32-33). The Elderly society of Ahwaz city with this background on urban regions evaluated their community with a participatory view to their community and the factors which trace that variable (32-33).

According to the findings, social dependency has the highest effect on civic engagement of elder dwellers (14). That means the increasing dependency of aged citizens on their society for basic needs accompanied the growth of their own social participation. The variables such as fatalism, a sense of belonging to one's city, health status, and a sense of satisfaction of urban services have more significant relationships with civic engagement of ageing (38-39). Thus the data indicated that there is no significant relationship between civic engagement and religiosity and did not show any difference between religiosity and social participation (19-22).

It is important to mention the neutral variable and non-effective status of religiosity for participatory interactions of aged citizens. In marital status, those widow elders have more participation in the community than others and this difference was significant. There is a significant relationship between socioeconomic status and social participation. The result showed that the aging people who live in low and poor socioeconomic status and public health indexes have less participation in the social activity (59-60). Finally, the potential utility of approach to physical activity programming, civic engaging at community level and elderly intervention that targets those values and beliefs held valuable by many in older adult community deserves greater attention. Such values and beliefs include contributing positively to society and to subsequent generations, maintaining independence, providing a legacy of betterment to one's culture and community, upholding cultural values and traditions, honouring those who passed away, and protecting lives and livelihoods of one's coming descendent. Through capturing such societal values, more potent and sustainable solutions to this major public health challenge will be enacted. Such solutions may in turn 
produce important benefits to the individual while paving the ground for greater civic engagement and community contribution that can fulfil the promise of a long life (14, 30-33, 36-38, 61).

Data availability, accessibility to the older adults settling in nursing homes and/or day care centres, illiterate aging people could be termed as limitations of the research. Noticeably, through having a Gerontological view socially to the elderly people's lives and their participatory interactions and giving a connection to bio-psychosocial dimensions of elderly citizens' lives in Iran and Khuzestan province could be demonstrated as the strong milestones of the study as well.

\section{Ethical Considerations}

Ethical matters e.g. plagiarism, informed consent, misconduct, data fabrication and/or falsification, double publication and/or submission, redundancy, etc. have been totally observed by the authors.

\section{Conflict of interests}

The authors declare that they have no competing interests.

\section{Author's contributions}

L.Fani Saberi and F.Rezaie Abhari have contributed to the design, performing the interviews, A.Asadollahi has written the draft and contributed to design, interpreting the discussion, revising the content, and approving the final manuscript as well.

\section{Acknowledgements}

The authors sincerely appreciate the editor, all colleagues, and the anonymous referees for their valuable comments.

\section{References}

1. Armstrong GK, Morgan K. Stability and Change in Levels of Habitual Physical Activity in Later Life. Age Ageing 1998; 27-S3: 17-23.

2. Asadollahi A. Social quality and Social Well-being for
Aged People; toward measuring and understanding in community level, Saarbrucken, Germany: Lambert Academic Publishing Company 2011.

3. Bennett KM. Gender and longitudinal changes in physical activity in later life. Age Ageing 1998; 27-S3: 24-28.

4. Klumb PL, Baltes MM. Timely Use of Old and Very Old Berliners: productive and consumptive activities as functions of resources. Journal of Gerontology: Social Sciences 1999; 54B, S271-S278.

5. Strain LA, Grabusic CC, Searle MS, Dunn NJ. Continuing and Ceasing Leisure Activities in Later Life: a longitudinal study. Gerontologist 2002; 42(2): 217-223.

6. Levasseur M, Desrosiers J, Noreau L. Is Social Participation Associated With Quality of Life Of Older Adults with Physical Disabilities? Disabled Rehab 2004; 26(20): 1206-13.

7. Noreau L, Desrosiers J, Robichaud L, Fougeyrollas P, Rochette A, Viscogliosi C. Measuring Social Participation: Reliability of the LIFE-H in Older Adults with Disabilities. Disabil Rehabil 2004; 26(6): 346-52.

8. Levasseur M, Desrosiers J, St-Cyr Tribble D. Do Quality of Life, Participation and Environment of Older Adults Differ According to Activity Level? Health Quality Life Outcomes 2008.

9. Desrosiers J, Robichaud L, Demers L, Gélinas I, Noreau L, Durand D. Comparison and Correlations Of Participation in Older Adults without Disabilities. Arch Gerontol Geriatrics 2009; 49(3): 397-403.

10. Desrosiers J, Wanet-Defalque MC, Témisjian K, Gresset J, Dubois MF, Renaud J, et al. Participation in Daily Activities and Social Roles of Older Adults with Visual Impairment. Disabled Rehab 2009; 31(15): 1227-34.

11. Demers L, Robichaud L, Gélinas I, Noreau L, Desrosiers J. Coping Strategies and Social Participation in Older Adults. Gerontology 2009; 55(2): 233-9.

12. Towers C. Living through Transition: The concerns of older people when relocated to residential care. Doctoral thesis in progress. Nottingham: Nottingham Trent University 2003.

13. Asadollahi A. Social Participation and General Health of Aged Citizens in Khuzestan Province (Iran): Literature, Factors, and Obstacles. World Applied Science Journal 
2011; 13(6): 1512-1522.

14. Asadollahi A. An Analysis of Inequality of Public Sphere and Health Status of Aging Communities in Khuzestan Province, Iran. J Nutr Health Aging 2013; 17(1): 378.

15. Lauder W, Mummery K, Sharkey S. Social Capital, Age, and Religiosity in People Who are Lonely. J Clin Nurs 2006; 15(3): 334-40.

16. Worthington EL, Kurusu TA, Mc-Cullough ME, Sandage SJ. Empirical Research on Religion and Psychotherapeutic Outcome: A 10 year review and research prospectus. Psychol Bull 1996; 119(3): 448487.

17. Booth ML, Owen N, Bauman A, Clavisi O, Leslie E. Social-Cognitive and Perceived Environment Influences Associated with Physical Activity in Older Australians. Preventive Med 2000; 31(1): 15-22.

18. Fly JW, Reinhart GR, Hambry R. Leisure activity and adjustment in retirement. Sociol Spectr 1981; 1(2): 135-144.

19. Chokkanathan S. Religiosity and Well-being of Older Adults in Chennai, India. Aging Ment Health 2013; 17(7): 880-7.

20. Wang KY, Kercher K, Huang JY, Kosloski K. Aging and Religious Participation in Late Life. J Religious Health 2013.

21. Kahn JH, Hessling RM, Russell DW. Social Support, Health, and Well-being among the Elderly: What is the role of negative affectivity? Personality and Individual Differences 2003; 35(1): 5-17.

22. Zenevicz L, Moriguchi Y, Madureira VS. The Religiosity in the Process of Living Getting Old. Rev Esc Enferm USP 2013; 47(2): 433-9.

23. Kelty MF, Hoffman RR, Ory MG, Harden JT. Behavioral and Sociocultural Aspects of Aging, Ethnicity, and Health. Handbook of Gender, Culture, and Health. Mahwah, NJ: Erlbaum 2000; 139-158.

24. Corrêa AA, Moreira-Almeida A, Menezes PR, Vallada $\mathrm{H}$, Scazufca M. Investigating the Role Played by Social Support in the Association between Religiosity and Mental Health in Low Income Older Adults: Results From The São Paulo, Ageing \& Health Study (SPAH). Rev Bras Psiquiatr. 2011; 33(2): 157-64.

25. Biggs S. toward a Critical Narration: Stories of Aging in Contemporary Social Policy. J Aging Stud 2001; 15(4): 303-316.

26. Carter T, Beresford P. Models of Involvement of Older People. Joseph Rowntree Foundation 1999.

27. Coleman D, Iso-Ahola SE. Leisure and Health: the Role of Social Support and Self-Determination. J Leis Res 1993; 25(2): 111-128.

28. Simpson EE, O'Connor JM, Livingstone MBE, Rae G, Stewart-Knox BJ, Andriollo-Sanchez M, et al. Health \&lifestyle Characteristics of Older European Adults: the ZENITH study. Eur J Clin Nutr 2005; 59 :S13-S21.

29. Wolff Kurt H. The sociology of Georg Simmel. New York: MacMillan; 1950.

30. Patterson I. Participation in Leisure Activities by Older Adults after a Stressful Life Event: The Loss of a Spouse. Int J Aging Hum Dev 1996; 42(2): 123-142.

31. Padgett D. Aging Minority Women. Gender, Culture, and Ethnicity: Current Research about Women and Men. Mountain View, CA: Mayfield 1999: 173-181.

32. Asadollahi A, Ahmad N, Valizadeh SH, Baratvand M. Social Quality for Aged People in Iran: Towards Developing Theoretical Scale, Qualite Sociale Pour Les Personnes Agees En Iran: Vers Le Developpement D'une Echelle Theorique. Canadian Social Science 2011; 7(6): 162-176.

33. Asadollahi A. Social Capital for Aged People in Khuzestan Province, Iran: Toward Developing a Scale. In ISI Indexed of 2011 International Conference on Social Science and Humanity Handbook. IPEDR 2011; 5. Singapore: IACSIT Press.

34. Yeh SCJ, Liu YY. (2003). of Social Support Influencing Cognitive Function in the Elderly. BMC Health Serv Res. Available http://www.ncbi.nlm.nih.gov/pmc/ articles/PMC161808/. Late September, 24, 2010.

35. Glass TA, De Leon CM, Bassuk SS, Berkman LF. Social Engagement and Depressive Symptoms in Later Life: Longitudinal Findings. J Aging Health 2006; 18(4): 604-28.

36. King A, King D. Physical Activity for an Aging Population. Public Health Reviews 2010; 32 (2): 401-26.

37. Galloway MT, Jokl P. Aging Successfully: The Importance of Physical Activity in Maintaining Health and Function. J Am Acad Orthop Surg. 2000 ;8(1): 37-44.

38. Larzelere MM, Campbell J, Adu-Sarkodie NY. 
Psychosocial Factors in Aging. Clin Geriatr Med 2011; 27(4): 645-60.

39. Okun MA, Yeung EW, Brown S. Volunteering by Older Adults and Risk of Mortality: A Meta-Analysis. Psychol Aging 2013; 28(2): 564-77.

40. Desrosiers J, Bourbonnais D, Noreau L, Rochette A, Bravo G, Bourget A. Participation after Stroke Compared to Normal Aging. J Rehabil Med 2005; 37(6): 353-7.

41. Carpenter C, Forwell SJ, Jongbloed LE, Backman CL. Community Participation after Spinal Cord Injury. Arch Phys Med Rehabil 2007; 88(4): 427-33.

42. Whiteneck G, Meade MA, Dijkers M, Tate DG, Bushnik T, Forchheimer MB. Environmental Factors and Their Role in Participation and Life Satisfaction after Spinal Cord Injury. Arch Phys Med Rehabil. 2004; 85(11): 1793-803.

43. Silverstein M, Parker MG. Leisure Activities and Quality of Life among the Oldest Old in Sweden. Res Aging 2002; 24(5): 528-547.

44. Triado C, Villar F, Sole C, Celdran M, Osuna MJ. Daily Activity and Life Satisfaction in Older People Living in Rural Contexts. Span J Psychol 2009; 12(1): 236-45.

45. Adams KB, Leibbrandt S. Moon H. A Critical Review of the Literature on Social and Leisure Activity and Wellbeing in Later Life. Ageing Soc 2011; 31(4): 683-712.

46. Hu FB, Li TY, Colditz GA, Willet WC, Manson JE. Television Watching and Other Sedentary Behaviors in Relation to Risk of Obesity and Mellitus Diabetes Type 2 in Women. JAMA 2003; 289(14): 1785-1791.

47. Menec VH. The Relation between Everyday Activities and Successful Aging: A 6-Year Longitudinal Study. J Gerontol B Psychol Sci Soc Sci 2003; 58(2): S74-S82.

48. Saint-Onge J.M. (2008). Race/Ethnic and Gender Differences in Depression: The Role of Social Support and Leisure Time Physical Activity. 2009 Annual Meeting: Population Association of America, Detroit: April 30-May 2 .

49. Chen SY, Fu YC. Leisure Participation and Enjoyment among the Elderly: Individual Characteristics and Sociability. Educ Gerontol 2008; 34(10):871-89.

50. Kåreholt I, Lennartsson C, Gatz M, Parker MG. Baseline Leisure Time Activity and Cognition More Than Two Decades Later. Int J Geriatr Psychiatry 2011;
26(1):65-74.

51. ISCC. National Census of Iran; an Annual report. Tehran: Iran Statistic \& Census Centre 2011.

52. ISCC. Iranian Family and Economic; an Annual Report, (Rep. No. 90/REP.43). Tehran: Iran Statistic \& Census Centre; 2012.

53. WHO. The Country Brief Report; IRAN on 2005. World Bank Organization [Electronic version]. Retreived from: www.worldbank.org/iranreport.html, on July 2013.

54. KSCC. Local Census of Khuzestan Province on 2007. Ahwaz, Iran: Khuzestan Statistic \& Census Centre;2007.

55. Mack N, Woodsong C, MacQueen KM, Guest G, Namey E. In-depth Interviewing. In Mack N, Woodsong C, MacQueen KM, Guest G, Namey E. Qualitative Research Methods: A Data Collector's Field Guide. Research Triangle Park, NC: Family Health International 2005.

56. The Center for Information \& Research on Civic Learning and Engagement, CIRCLE. 2006 Civic and Political Health of the Nation. National Report. Washington DV: CIRCLE; 2010. Retrieved from: http://www.civicyouth.org/2006-civic-and-politicalhealth-of-the-nation/?cat_id=0. Retrieved in 8.17.2013.

57. Putnam R. Ed. Democracies in Flux: The Evolution of Social Capital in Contemporary Society. USA: Oxford University Press 2004.

58. Mohammadi H. Civic Engagement, Political Participation and Good Government in Iran. PhD Diss. in Social Development. Kuala Lampur, Malaysia: University of Putra Malaysia 2012.

59. Dykstra P. Age Differences in Social Participation: the Importance of Restrictions. In C. P. M. Knipscheer J. de Jong Gierveld T. G. van Tilburg \& P. A. Dykstra (Eds.), Living Arrangements and Social Networks of Older Adults. Amsterdam: VU University Press; 1995: 59-82.

60. Kamilar CB, Segal DL, Qualls SH. Role of Gender and Culture in the Psychological Adjustment to Aging. In Eisler RM, Hersen M (Eds.), Handbook of Gender, Culture, and Health. Mahwah, NJ: Erlbaum; 2000: 405-428.

61. Laidmäe V, Tammsaar K, Tulva T, Kasepalu U. Quality of Life of Elderly in Estonia. Int $\mathrm{J}$ of Ger and Geron 2012; 7(1): 31-37. 